\title{
Clinical Application of Shear Wave Elastography in Breast Masses
}

\author{
Jin Young Chang, ${ }^{1}$ Jin Hee Moon, ${ }^{1,}{ }^{*}$ Sung Hye Koh, ${ }^{1}$ Sun-Young Park, ${ }^{1}$ and Kwan Seop Lee ${ }^{1}$ \\ ${ }^{1}$ Hallym Sacred Heart Hospital, Anyang, Republic of Korea \\ "Corresponding author: Jin Hee Moon, Hallym Sacred Heart Hospital, Anyang, Republic of Korea. Tel: +82-313805969, E-mail: geenie-m@hanmail.net
}

Received 2016 May 30; Revised 2016 July 05; Accepted 2016 August 01.

\begin{abstract}
Background: Quantitative shear wave elastography (SWE) has been developed and utilized to aid in the differentiation between benign and malignant breast lesions based on their stiffness.

Objectives: The purpose of this study was to evaluate the clinical effects of the additional use of SWE to conventional ultrasound (US) according to the maximum (Emax) and mean (Emean) elasticitiy values.

Patients and Methods: A total 115 patients with 133 lesions were assessed using conventional US and SWE. All patients underwent US-guided core needle biopsy or surgery, and the pathological results were used as reference standards. We compared the diagnostic values including sensitivities, specificities, positive predictive values (PPVs) and negative predictive values (NPVs) and accuracies of conventional US and SWE according to the $\mathrm{E}_{\max }$ and $\mathrm{E}_{\mathrm{mean}}$ values. Next, we obtained the optimal $\mathrm{E}_{\max }$ and $\mathrm{E}_{\operatorname{mean}}$ cutoff values for SWE. Using these cutoff values, we analyzed the clinical effects of the additional use of SWE to conventional US based on the corrected results.

Results: Of the 133 breast lesions, 32 were malignant and 101 were benign. In the differentiation of benign and malignant lesions, conventional US resulted in sensitivity of $100 \%$, specificity of $43.0 \%$, PPV of $57.1 \%$, NPV of $36.7 \%$, and accuracy of $100 \%$. Regarding SWE, the sensitivity, specificity, PPV, NPV, and accuracy values based on $\mathrm{E}_{\max }$ were $84.4 \%, 89.1 \%, 71.1 \%, 94.7 \%$, and $88.0 \%$, respectively, and the corresponding values based on $\mathrm{E}_{\text {mean }}$ were $84.8 \%, 93.0 \%, 91.0 \%, 80.0 \%$, and $94.9 \%$, respectively. The optimal $\mathrm{E}_{\max }$ and $\mathrm{E}_{\operatorname{mean}}$ cutoff values were 81.3 and $60.7 \mathrm{kPa}$, respectively. However, there was no significant difference between $\mathrm{E}_{\max }$ and $\mathrm{E}_{\text {mean }}$. The corrected results related to the additional use of SWE to conventional US indicated $97.0 \%$ sensitivity, $93.0 \%$ specificity, $82.1 \%$ PPV, $98.9 \%$ NPV, and $94.0 \%$ accuracy $(\mathrm{P}<0.0001)$.

Conclusion: The additional use of SWE to conventional US resulted in marked improvements in specificity, PPV, and accuracy and slight diminutions in sensitivity and NPV for the differentiation benign and malignant breast lesions. Both $\mathrm{E}_{\max }$ and $\mathrm{E}_{\text {mean }}$ were effective diagnostic parameters, and there was no significant difference between these two parameters.
\end{abstract}

Keywords: Breast, Ultrasound, Elastography, Shear Wave, Solid Mass

\section{Background}

Elastography has developed rapidly and has been used to help differentiate between benign and malignant lesions based on their stiffness $(1,2)$. Malignant lesions of the breast tend to be stiffer than benign lesions, thus elastography imaging promises to be a highly specific method for distinguishing benign and malignant breast lesions and it also has the potential to reduce the number of benign breast biopsies performed (3-5). However, strain elastography with the color map has several limitations because the acquired information is operator dependent and nonquantitative $(6,7)$.

Shear wave elastography (SWE) has emerged as a promising technique for overcoming these limitations. SWE induces mechanical vibration of the tissue components using an acoustic radiation force that is generated by a focused ultrasound (US) beam. The displacement at the focus of the beam generates a shear wave that relays information associated with the local viscoelastic properties of the tissue and thereby facilitates a quantitative approach to determining elasticity values (8). An ultrafast US acquisition sequence is subsequently used to capture the propagation of the shear wave $(9,10)$. By setting the focus points at the regions of interest (ROIs), various quantitative elasticity values may be acquired.

Several studies have assessed SWE for the diagnosis of breast lesions and have demonstrated the potential of this technique as a diagnostic imaging modality that could provide more objective information $(8,9,11)$. However, accurate clinical effects of the additional use of SWE to conventional US have not been fully reported.

\section{Objectives}

The purpose of this study was to assess the clinical effects of the additional use of SWE according to maximum elasticity $\left(E_{\max }\right)$ and mean elasticity $\left(E_{\text {mean }}\right)$ values which are the most commonly used $(8,12,13)$. 


\section{Patients and Methods}

\subsection{Patient Selection and Data Collection}

The present study was approved by the institutional review board of Hallym university Sacred Heart hospital (Anyang-si, Korea). All of the patients included in the present study provided written informed consent.

Breast US and US-guided biopsies were performed on 134 consecutive patients who were admitted to Hallym university Sacred Heart hospital between November 2014 and March 2015. Of these patients, 19 refused to undergo the SWE procedure; therefore, the final analysis was based on data acquired from 115 patients (mean age: 51.4 years; age range, 33- 80 years) who exhibited 133 lesions as detected by US. Histopathology results were obtained for all patients based on US-guided core needle biopsy (14-gauge auto- or semi-automated gun, Stericut, TSK, Laboratory) or surgical excision samples. Histopathology results from the biopsies and surgeries served as the reference standards.

\subsection{Image Acquisition, US and Elastography}

Conventional US examinations were conducted using a 5 - $12 \mathrm{MHz}$ linear transducer on an HDI 5000 sonography unit or an IU-22 (Phillips Healthcare, Andover, MA, USA) by two experienced radiologists with 4 - 6 years of experience in breast imaging.

The US features of each lesion were evaluated according to the fourth edition of the breast imaging reporting and data system (BI-RADS) prior to biopsy or surgery, and the lesions were graded as follows: category 0 , assessment incomplete; category 1 , negative; category 2 , benign finding; category 3, probably benign; category 4A, low suspicion of malignancy; category $4 \mathrm{~B}$, intermediate suspicion of malignancy; category $4 \mathrm{C}$, moderate suspicion of malignancy; category 5, highly suspicious of malignancy, appropriate action should be taken; and category 6, known biopsy-proven malignancy, treatment pending (14).

Following conventional US, SWE was performed on the targeted lesions by the same radiologists who performed the initial conventional US. The Aixplorer ${ }^{\circledR}$ system (Super Sonic Imagine, Aix en Provence, France) was used and the SWE images were obtained by applying a 15- to 4- $\mathrm{MHz}$ linear transducer lightly to the skin above the targeted lesion with a generous quantity of gel. The probe was kept still without compression for a few seconds to capture elastography images of adequate quality. The conventional US and SWE images were displayed in split-screen mode, and the SWE image was superimposed onto the corresponding B-mode grey-scale US image. The tissue elasticity of each pixel in the SWE image was acquired using a color-coded map that represented Young's moduli (kPa), over a range (range, 0 - $180 \mathrm{kPa}$ ) from dark blue (soft) to red (stiff). The elasticity image was refreshed in real time.

The quantitative elasticity values were determined by locating lesions to the centers of an ROI box with default areas of $2.5 \times 1.5 \mathrm{~cm}$ and maximal areas of $3.0 \times 2.5 \mathrm{~cm}$ (8). The radiologists placed a $2 \mathrm{~mm}$ sized, round quantification ROI onto the previously generated color maps. The ROI was positioned on the stiffest portion of each lesion, including the immediately adjacent stiff tissue or halo (12). During this process, several values related to SWE evaluation were automatically calculated and displayed on a screen. Among the several values, $\mathrm{E}_{\max }$ and $\mathrm{E}_{\text {mean }}$ values of all analyzed lesions were recorded for subsequent analyses. $E_{\max }$ and $E_{\text {mean }}$ were automatically calculated by software and each lesion was assessed at least twice and the average value was recorded. The acquisition of the SWE images required approximately $2-3 \mathrm{~min} /$ case.

As an important factor influencing image quality of $\operatorname{SWE}(7,15,16)$, we recorded lesion depth (vertical diameter from the skin to the center of the breast mass) and distance from the nipple (measured from the nipple to the margin closest to the nipple) and divided them into three groups as superficial, mid, and deep. And we compared the difference of $E_{\max }$ and $E_{\text {mean }}$ according to lesion depth.

\subsection{Statistical Analysis}

The McNemar test was used to calculate the sensitivities, specificities, positive predictive values (PPVs), negative predictive values (NPVs), and accuracies of conventional US and SWE based on the applications of $\mathrm{E}_{\max }$ and $\mathrm{E}_{\text {mean }}$ values for subsequent comparison of the diagnostic accuracies. The optimal $\mathrm{E}_{\max }$ and $\mathrm{E}_{\text {mean }}$ cutoff values that yielded the maximal sums of the sensitivities and specificities were calculated. Additionally, the area under the receiver operating characteristic (ROC) curve (Az value) was calculated using each cutoff value to evaluate the diagnostic performances of $E_{\max }$ and $E_{\text {mean }}$ values. Statistically significant differences between $\mathrm{Az}$ values are reported with 95\% confidence intervals. Following the individual ROC analysis of each examination, the optimal cutoff values determined in the present study were used to analyze and compare the diagnostic performances of conventional US in addition to SWE and conventional US alone. The two sample t-test was used to compare the difference of average $\mathrm{E}_{\max }$ and $\mathrm{E}_{\text {mean }}$ according to lesion depth in SWE. The Stata software (release version 9.0; Stata corporation, college station, TX, USA) was used for all statistical analyses. The values of $\mathrm{P}$ $<0.05$ were considered to indicate a statistically significant difference. Intra-observer variability was calculated using Kappa statistics. Agreement was defined based on the Fleiss classification as follows: 0.40, poor; $0.40-0.59$, moderate; 0.60 - 0.75, good; and 0.75, excellent $(17,18)$. 


\section{Results}

Of the 133 lesions identified in the 115 patients who were evaluated in the present study, 32 lesions were classified as malignant and 101 were diagnosed as benign. The mean size of the 133 lesions was $14.2 \mathrm{~mm}$ with a range of 4 to 28 $\mathrm{mm}$. The subtypes of the malignant and benign lesions are listed in Figure 1.

On conventional US, the sensitivity, specificity, PPV, NPV, and accuracy were $100.0 \%, 43.0 \%, 57.1 \%, 36.7 \%$ and $100 \%$, respectively. On $\mathrm{SWE}$, using either $\mathrm{E}_{\max }$ or $\mathrm{E}_{\text {mean }}$, there were substantial differences compared with conventional US. The sensitivity, specificity, PPV, NPV, and accuracy were $84.4 \%, 89.1 \%, 71.1 \%, 94.7 \%$, and $88.0 \%$, respectively, based on $\mathrm{E}_{\max }$ and the corresponding values on $\mathrm{E}_{\text {mean }}$ were $84.8 \%$, 93.0\%, 91.0\%, 80.0\%, and 94.9\%, respectively (Table 1). Using either $E_{\max }$ or $E_{\text {mean }}$, SWE exhibited lower sensitivity but higher specificity, accuracy and PPV relative to conventional US $(\mathrm{P}<0.0001)$.

Optimal $\mathrm{E}_{\max }$ and $\mathrm{E}_{\text {mean }}$ cutoff values obtained during SWE, i.e., those that yielded the maximal sums of the sensitivities and specificities, were 81.3 (sensitivity, $84.8 \%$; specificity, 89.1\%) and $60.7 \mathrm{kPa}$ (sensitivity, $84.4 \%$; specificity, 93.0\%), respectively. There was no significant difference between the use of optimal Emax and Emean cutoff values to differentiate between the benign and malignant lesions ( $P$ $=0.1797$ ).

The ROC curves for $\mathrm{E}_{\max }$ and $\mathrm{E}_{\text {mean }}$ are displayed in Figure 2. Az values were 0.8884 (standard error, $0.0434 ; 95 \%$ confidence interval, 0.80293 - 0.97306) for $\mathrm{E}_{\max }$ and 0.8908 (standard error, 0.0423; 95\% confidence interval, 0.80805 - 0397382) for $E_{\text {mean }}$. These results indicated that $E_{\max }$ and $E_{\text {mean }}$ elasticity values were equivalently beneficial for differentiating between benign and malignant lesions ( $\mathrm{P}=$ 0.5028).

The diagnostic performances related to the additional use of SWE to conventional US compared to that of conventional US alone were investigated using the optimal cutoff values determined in the present study. Table 2 provides the corrected results when $\mathrm{E}_{\max }$ and $\mathrm{E}_{\text {mean }}$ cutoff values were applied to lesions categorized as 3 or $4 \mathrm{~A}$. Correcting the data resulted in significant improvements in the specificity, accuracy and PPV $(\mathrm{P}<0.0001)$ and slight diminutions of the sensitivity and NPV.

Of 32 malignant lesions, eight were superficial, 18 were mid and six were deep location and of 101 benign lesions, 25 were superficial, 62 were mid and 14 were deep location. Mean of $E_{\max }$ showed statistically significant difference between malignant and benign lesions only in deep located lesions $(\mathrm{P}=0.019)$. The intraobserver agreements of two radiologists were excellent with regard to elastography $(\mathrm{K}=$ 0.8689).

\section{Discussion}

Several reports have demonstrated the diagnostic accuracy of $\operatorname{SWE}(2,8,12,19,20)$. However, radiologists usually use this technique in addition to conventional US. Thus, we investigated the corrected results of the additional use of SWE to conventional US compared with those of conventional US alone. Moreover, we analyzed the differences between $\mathrm{E}_{\mathrm{max}}$ and $\mathrm{E}_{\mathrm{mean}}$, which are the most commonly used parameters.

The current study revealed that the additional use of SWE to conventional US was clinically useful and markedly improved the specificity, PPV and accuracy. However, this approach also resulted in slight diminutions of sensitivity and NPV.

Sensitivity and NPV of conventional US in this study were both $100 \%$. A large number of studies have demonstrated that breast US is already highly sensitive (21-24). However, the specificity of US is relatively low, and a high rate of benign biopsies based on US has also been reported (20, 25-27). In the present study, the additional use of SWE to conventional US reduced the rate of benign lesion biopsy by $46.0 \%$ to $85.7 \%$. This result is similar to those others have reported $(8,28,29)$. In BI-RADS category 3 cases, biopsies are frequently performed at the request of the clinician or patient. Additionally, certain category 3 or $4 \mathrm{~A}$ breast lesions exhibit overlapping benign and malignant features that may induce false-negative results. Histopathology indicated that $100 \%$ of category 3 lesions and $97 \%$ of category $4 \mathrm{~A}$ lesions were benign. This high negative biopsy rate indicated that the decision to perform a biopsy is most often required for category 3 and $4 \mathrm{~A}$ breast lesions. It has been hypothesized that use of $\mathrm{E}_{\mathrm{max}}$ and $\mathrm{E}_{\text {mean }}$ cutoff values to reassess lesions that are incorrectly assessed as category 3 or $4 \mathrm{~A}$ based on conventional US would reduce the numbers of false-negative and false-positive cases. In the present study, application of $\mathrm{E}_{\mathrm{max}}$ and $\mathrm{E}_{\text {mean }}$ cutoff values to category 3 and $4 \mathrm{~A}$ lesions resulted in improvements in specificity and accuracy (Table 1). Therefore, the current results indicate that the use of quantitative SWE with cutoff values, in combination with conventional US, may facilitate the differentiation of breast lesions, particularly those categorized as 3 or $4 \mathrm{~A}$ based on conventional US alone. Both $\mathrm{E}_{\mathrm{ma}} \mathrm{x}$ and $\mathrm{E}_{\text {mean }}$ values were effective diagnostic parameters.

Regarding the assessment of elasticity, SWE provides several parameters. Maximum $\left(\mathrm{E}_{\max }\right)$, mean $\left(\mathrm{E}_{\text {mean }}\right)$ and minimum $\left(E_{\min }\right)$ stiffness represent the general stiffness of the mass. Moreover, elasticity ratio (Eratio) indicates the relative stiffness of the mass to that of fat tissue and standard deviation (SD) indicates the internal heterogeneity of the mass. All of these parameters can help to im- 


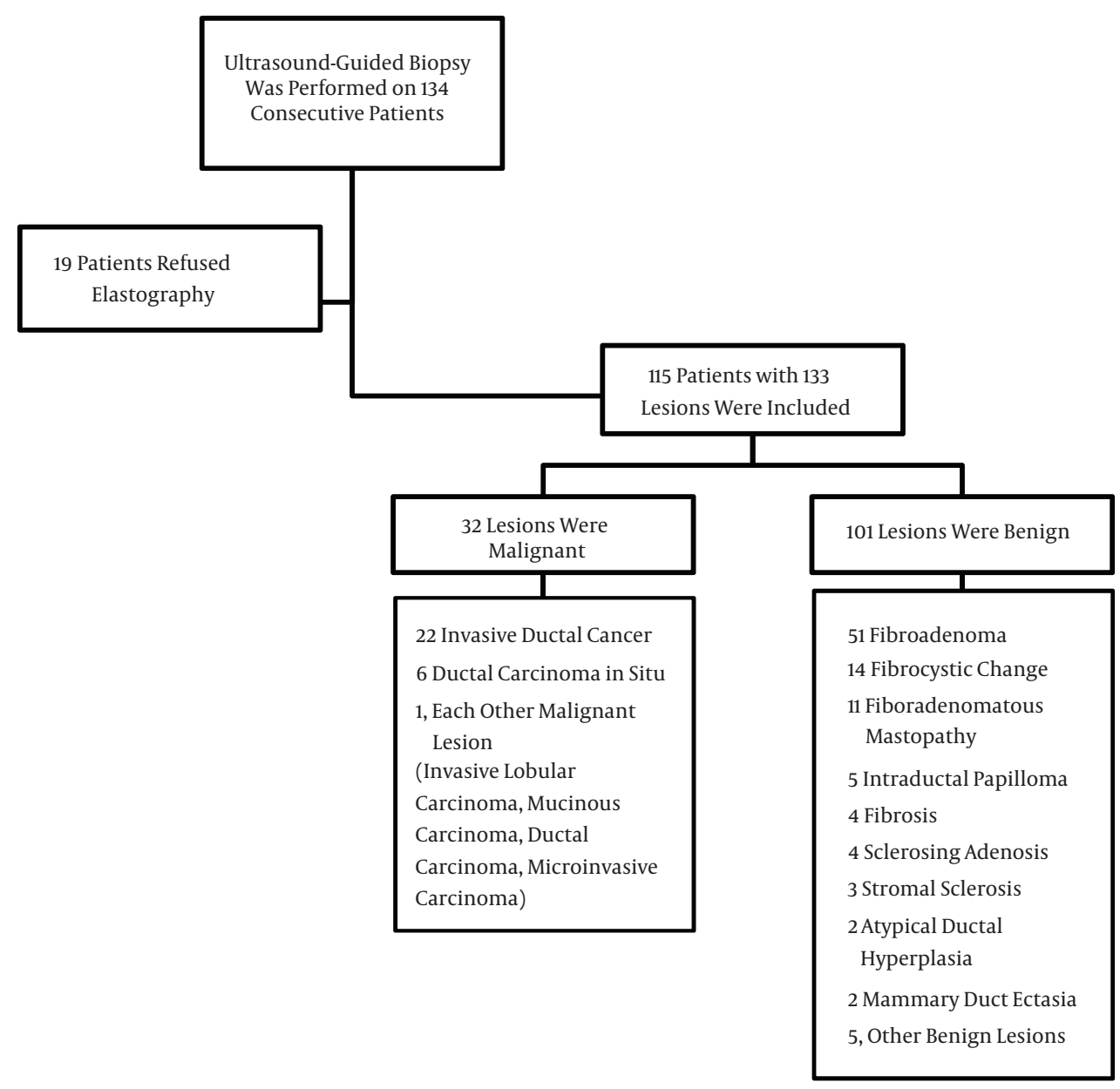

Figure 1. Flowchart of participants and the number of benign and malignant lesions and their subtypes

Table 1. Statistical Analysis of Conventional US and SWE

\begin{tabular}{|c|c|c|c|c|c|c|}
\hline \multirow{2}{*}{$\begin{array}{l}\text { Imaging } \\
\text { Modality }\end{array}$} & \multicolumn{5}{|c|}{ Performance Measure } & \multirow[t]{2}{*}{ PValue } \\
\hline & $\begin{array}{c}\text { Sensitivity, \% (95\% } \\
\text { CI) }\end{array}$ & $\begin{array}{l}\text { Specificity, \% (95\% } \\
\text { CI) }\end{array}$ & PPV, \% (95\% CI) & NPV, \% (95\% CI) & Accuracy, \% (95\% CI) & \\
\hline $\begin{array}{l}\text { Conventional } \\
\text { US }\end{array}$ & $100(1.0000-1.0000)$ & $43.0(0.3330-0.5270)$ & $57.1(0.4873-0.6555)$ & $36.7(0.2671-0.4662)$ & $\begin{array}{l}100.0(1.0000- \\
\quad 1.0000)\end{array}$ & $<0.0001$ \\
\hline \multicolumn{7}{|l|}{ SWE } \\
\hline $\mathrm{E}_{\max }$ & $84.4(0.7179-0.9696)$ & $89.1(0.8303-0.9518)$ & $71.1(0.5663-0.8547)$ & $94.7(0.9025-0.9923)$ & $88.0(0.8244-0.9350)$ & $<0.0001$ \\
\hline$E_{\text {mean }}$ & $84.8(0.7262-0.9708)$ & $93.0(0.8800-0.9800)$ & $91.0(0.8611-0.9585)$ & $80.0(0.6675-0.9325)$ & $94.9(0.9054-0.9925)$ & $<0.0001$ \\
\hline
\end{tabular}

Abbreviations: US, ultrasound; SWE, shear wave elastography; CI, confidence interval; PPV, positive predictive value; NPV, negative predictive value; Emax, maximum elasticity value; and Emean, mean elasticity value. 
Table 2. Statistical Analysis of Conventional US and Additional Use of SWE with Conventional US Using the Optical Cutoff Values

\begin{tabular}{|c|c|c|c|c|c|c|}
\hline \multirow{2}{*}{$\begin{array}{l}\text { Imaging } \\
\text { Modality }\end{array}$} & \multicolumn{5}{|c|}{ Performance Measure } & \multirow[t]{2}{*}{ PValue } \\
\hline & $\begin{array}{l}\text { Sensitivity, \% (95\% } \\
\text { CI) }\end{array}$ & $\begin{array}{l}\text { Specificity (\%) (95\% } \\
\text { CI) }\end{array}$ & PPV, \% (95\% CI) & NPV, \% (95\% CI) & Accuracy, \% (95\% CI) & \\
\hline $\begin{array}{l}\text { Conventional } \\
\text { US } \\
\end{array}$ & $100(1.0000-1.0000)$ & $43.6(0.3330-0.5270)$ & $52.1(0.4873-0.6555)$ & $36.0(0.2671-0.4662)$ & $100(1.0000-1.0000)$ & \multirow{2}{*}{$<0.0001$} \\
\hline $\begin{array}{l}\text { SWE + Con- } \\
\text { ventional } \\
\text { US }\end{array}$ & $97.0(0.8798-0.9994)$ & $93.0(0.8395-0.9876)$ & $82.1(0.7251-0.8994)$ & $98.9(0.9119-0.9968)$ & $94.0(0.8353-0.9844)$ & \\
\hline
\end{tabular}

Abbreviations: US, ultrasound; SWE, shear wave elastography; PPV, positive predictive value; NPV, negative predictive value; and SWE + conventional US, additional use of shear wave elastography to conventional ultrasound.

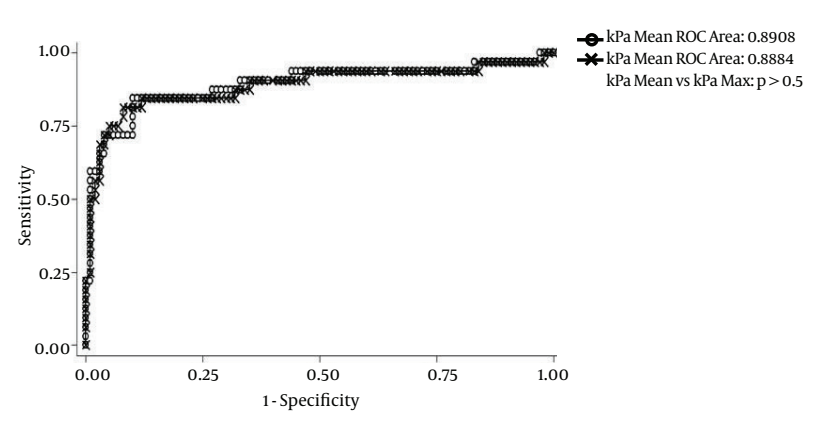

Figure 2. Receiver operating characteristic (ROC) curves for mean and maximum elasticity values. The area under the ROC curve is 0.8908 [standard error(SE), 0.0423; $95 \%$ confidence interval (CI), 0.80805 - 0.97382 ] for mean elasticity and 0.8884 (SE, $0.0434 ; 95 \% \mathrm{CI}, 0.80293$ - 0.97306) for max elasticity. These results indicated that the mean and maximum elasticity values were of equivalent benefit for differentiating benign and malignant lesions $(\mathrm{P}=0.5028)$.

prove the diagnostic accuracy of US. However, results regarding the identities of the most useful parameters vary across individual studies. Evans et al. reported that $\mathrm{E}_{\text {mean }}$ is more useful than $\mathrm{E}_{\max }$ and SD (13). Berg et al. reported optimal diagnostic performance with $\mathrm{E}_{\max }(12)$ and some studies have reported that SD alone exhibits excellent performance (11). In SWE, the parameters are obtained from a fixed ROI, which is generally the stiffest area, and SD does not reflect the heterogeneity of the entire lesion (19). Therefore, based on the combination of these studies, we focused on $\mathrm{E}_{\max }$ and $\mathrm{E}_{\text {mean }}$.

The present study determined an optimal $\mathrm{E}_{\text {mean }}$ cutoff value of $60.7 \mathrm{kPa}$. This value was lower than that reported by Chang et al. (8) (80.17 kPa) but similar to the values reported in other studies $(9,13)$. Similarly, the optimal cutoff value for $\mathrm{E}_{\max }$ determined in the present study $(81.3 \mathrm{kPa})$ was consistent with the findings of previous studies $(9,12)$.

There was one false negative case in this study (Figure 3). This case involved a $5 \mathrm{~mm}$ sized invasive ductal carcinoma (IDC). Although it has been reported that the size of a breast mass does not influence the diagnostic performance of elastography (30), smaller malignant masses tend to be early stage breast cancers that are composed of softer tissues than larger invasive masses, and this pattern may lead to false negative SWE resulted based on $\mathrm{E}_{\max }$ (15). Additional studies of the application of elastography to small sized, early stage breast cancer on elastography are anticipated in the future.

The present study showed statistical difference of average $\mathrm{E}_{\max }$ only in deep location. Several investigators indicated that the elasticity of deep located lesions could be affected by the chest wall $(15,16)$. However, $E_{\text {mean }}$ showed no statistical significant difference according to lesion depth. This is probably due to the small sized study group in deep location. Further evaluation might be necessary with a large study group about lesion depth.

There are several limitations to the present study. Notably, this study was a small, single-center study with a relatively low number of observers and patients with cancer. Therefore, a larger sample of patients with cancer is required to adequately assess the use of SWE for the diagnoses of soft tumors. Additionally, the present study was performed by radiologists who had only recently been introduced to the center and were thus, relatively inexperienced. This issue may have influenced the performance of the diagnostic imaging techniques. Therefore, with increased experience in elastography, an improved understanding of its value in the assessment of breast lesions may be obtained.

In conclusion, application of SWE appears to increase the diagnostic accuracy of conventional US in the diagnosis of breast lesions. Furthermore, for category 3 or $4 \mathrm{~A}$ lesions as assessed based on conventional US, use of SWE may reduce the rate of benign biopsies. Additionally, both $\mathrm{E}_{\max }$ and $E_{\text {mean }}$ values were effective diagnostic parameters and there was no significant difference between these two parameters. 

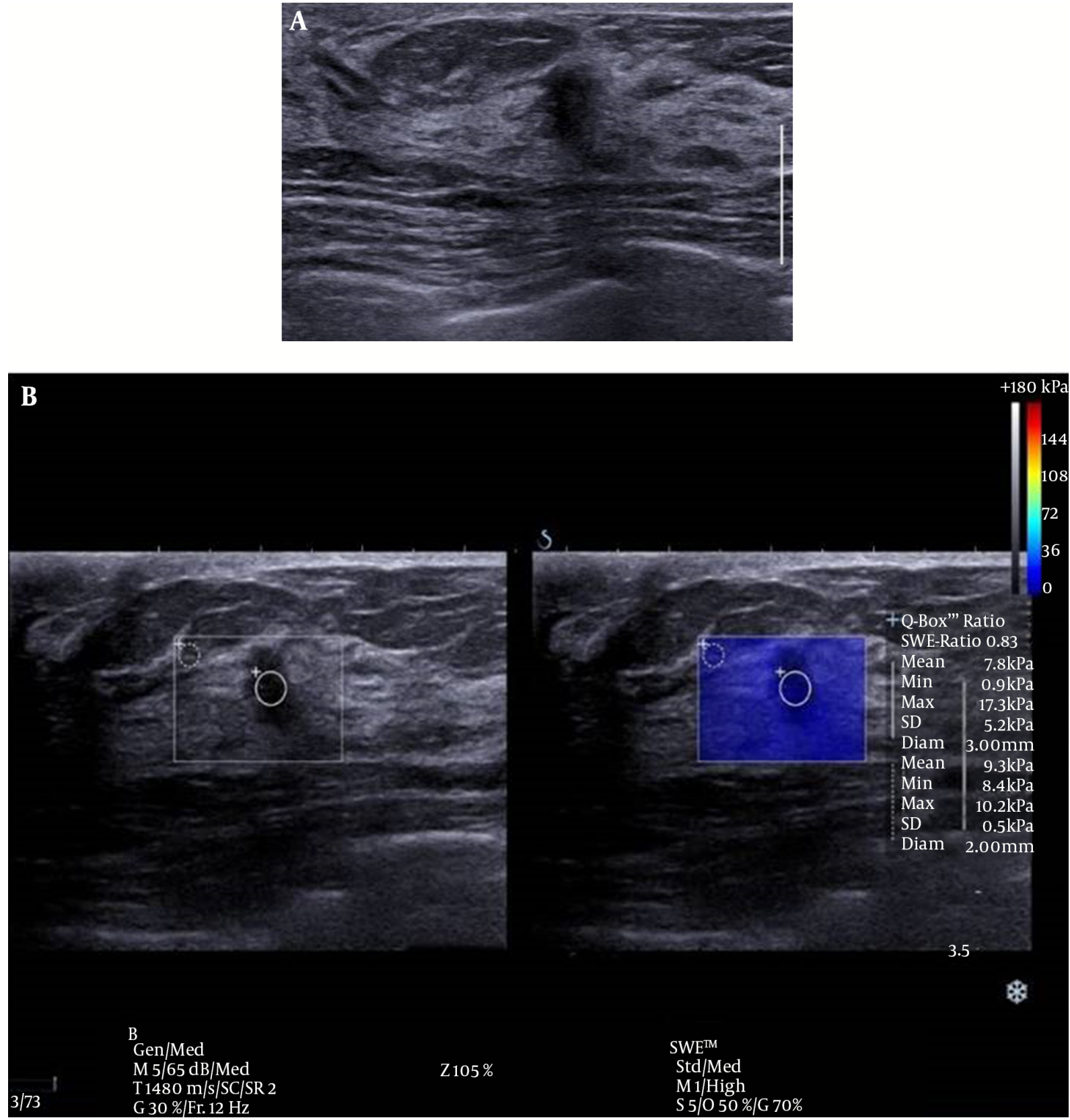

Figure 3. Conventional ultrasound (US) and shear wave elastography(SWE) of the breast of a 46-year-old female patient. A, conventional US imaging determined a true-positive result. An irregular, taller-than-wide orientated, hypoechoic lesion was identified and classified as category $4 \mathrm{C}$ on ultrasound, according to the breast imaging reporting and data system. B, SWE determined a false-negative result. The lesion exhibited a mean elasticity of $7.8 \mathrm{kPa}$ and a maximum of $17.3 \mathrm{kPa}$. This lesion was diagnosed as invasive ductal carcinoma. 


\section{Acknowledgments}

The authors thank Joo Yeon Cheung for editing this manuscript. And we also thank pathologists and breast surgeons in Hallym Sacred Heart hospital.

\section{Footnotes}

Authors' Contributions: Study conception and design: Jin Hee Moon; acquisition of data: Jin Hee Moon, Jin Young Chang; analysis and interpretation of data: Jin Hee Moon, Jin Young Chang; grafting of the manuscript: Jin Hee Moon; statistical analysis: Sung Hye Koh, Sun-Young Park; critical revision: Sung Hye Koh, Kwan Seop Lee

Financial Disclosure: None declared.

Funding/Support: We did not have any funding or support.

\section{References}

1. Ako Itoh M, Ei Ueno M, Eriko Tohno M, Hiroshi Kamma M, Hideto Takahashi P, Tsuyoshi Shiina P. Breast Disease: Clinical Application of US Elastography for Diagnosis. Radiology. 2006;239(2):341-50.

2. Garra BS, Cespedes EI, Ophir J, Spratt SR, Zuurbier RA, Magnant CM, et al. Elastography of breast lesions: initial clinical results. Radiology. 1997;202(1):79-86. doi: 10.1148/radiology.202.1.8988195. [PubMed: 8988195].

3. Raza S, Odulate A, Ong EM, Chikarmane S, Harston CW. Using realtime tissue elastography for breast lesion evaluation: our initial experience. J Ultrasound Med. 2010;29(4):551-63. [PubMed: 20375374].

4. Thomas A, Degenhardt F, Farrokh A, Wojcinski S, Slowinski T, Fischer T. Significant differentiation of focal breast lesions: calculation of strain ratio in breast sonoelastography. Acad Radiol. 2010;17(5):55863. doi:10.1016/j.acra.2009.12.006. [PubMed: 20171905].

5. Todd R, Kumm M, Margaret M, Szabunio MD. Elastography for the Characterization of Breast Lesions: Initial Clinical Experience. Cancer Control. 2010;17(3):156-61.

6. Burnside ES, Hall TJ, Sommer AM, Hesley GK, Sisney GA, Svensson WE, et al. Differentiating benign from malignant solid breast masses with US strain imaging. Radiology. 2007;245(2):401-10. doi:10.1148/radiol.2452061805. [PubMed: 17940302].

7. Chang JM, Moon WK, Cho N, Kim SJ. Breast mass evaluation: factors influencing the quality of US elastography. Radiology. 2011;259(1):5964. doi: 10.1148/radiol.10101414. [PubMed: 21330569].

8. Chang JM, Moon WK, Cho N, Yi A, Koo HR, Han W, et al. Clinical application of shear wave elastography (SWE) in the diagnosis of benign and malignant breast diseases. Breast Cancer Res Treat. 2011;129(1):89-97. doi: 10.1007/s10549-011-1627-7. [PubMed: 21681447].

9. Lee EJ, Jung HK, Ko KH, Lee JT, Yoon JH. Diagnostic performances of shear wave elastography: which parameter to use in differential diagnosis of solid breast masses?. Eur Radiol. 2013;23(7):1803-11. doi 10.1007/s00330-013-2782-5. [PubMed: 23423637].

10. Bercoff J, Tanter M, Fink M. Supersonic shear imaging: a new technique for soft tissue elasticity mapping. IEEE Trans Ultrason Ferroelectr Freq Control. 2004;51(4):396-409.

11. Gweon HM, Youk JH, Son EJ, Kim JA. Visually assessed colour overlay features in shear-wave elastography for breast masses: quantification and diagnostic performance. Eur Radiol. 2013;23(3):658-63. doi: 10.1007/s00330-012-2647-3. [PubMed: 22976918].
12. Berg WA, Cosgrove DO, Dore CJ, Schafer FK, Svensson WE, Hooley RJ, et al. Shear-wave elastography improves the specificity of breast US: the BE1 multinational study of 939 masses. Radiology. 2012;262(2):435-49. doi: 10.1148/radiol.11110640. [PubMed: 22282182].

13. Evans A, Whelehan P, Thomson K, McLean D, Brauer K, Purdie C, et al. Quantitative shear wave ultrasound elastography: initial experience in solid breast masses. Breast Cancer Res. 2010;12(6):104. doi: 10.1186/bcr2787. [PubMed: 21122101].

14. American College of Radiology . Breast imaging reporting and data system Atlas (BI-RADS Atlas). Reston: American College of Radiology; 2003. p. 98.

15. Yoon JH, Jung HK, Lee JT, Ko KH. Shear-wave elastography in the diagnosis of solid breast masses: what leads to false-negative or falsepositive results?. Eur Radiol. 2013;23(9):2432-40. doi: 10.1007/s00330013-2854-6. [PubMed: 23673572].

16. Ciurea AI, Bolboaca SD, Ciortea CA, Botar Jid C, Dudea SM. The influence of technical factors on sonoelastographic assessment of solid breast nodules. Ultraschall Med. 2011;32(01):27-34.

17. Landis JR, Koch GG. The measurement of observer agreement for categorical data. Biometrics. 1977;33(1):159-74. [PubMed: 843571].

18. Jones J, Hunter D. Consensus methods for medical and health services research. BMJ. 1995;311(7001):376-80. [PubMed: 7640549].

19. Cebi Olgun D, Korkmazer B, Kilic F, Dikici AS, Velidedeoglu M, Aydogan F, et al. Use of shear wave elastography to differentiate benign and malignant breast lesions. Diagn Interv Radiol. 2014;20(3):239-44. doi: 10.5152/dir.2014.13306. [PubMed: 24509183].

20. Itoh A, Ueno E, Tohno E, Kamma H, Takahashi H, Shiina T, et al. Breast disease: clinical application of US elastography for diagnosis. Radiology. 2006;239(2):341-50. doi: 10.1148/radiol.2391041676. [PubMed: 16484352].

21. Stavros AT, Thickman D, Rapp CL, Dennis MA, Parker SH, Sisney GA. Solid breast nodules: use of sonography to distinguish between benign and malignant lesions. Radiology. 1995;196(1):123-34. doi: 10.1148/radiology.196.1.7784555. [PubMed: 7784555].

22. Rahbar G, Sie AC, Hansen GC, Prince JS, Melany ML, Reynolds HE, et al. Benign versus malignant solid breast masses: US differentiation. $R a$ diology. 1999;213(3):889-94. doi: 10.1148/radiology.213.3.r99dc20889. [PubMed: 10580971].

23. Hong AS, Rosen EL, Soo MS, Baker JA. BI-RADS for sonography: positive and negative predictive values of sonographic features. AJR Am J Roentgenol. 2005;184(4):1260-5. doi: 10.2214/ajr.184.4.01841260. [PubMed: 15788607].

24. Gordon PB, Goldenberg SL. Malignant breast masses detected only by ultrasound. A retrospective review. Cancer. 1995;76(4):626-30. [PubMed: 8625156].

25. Zhi H, Ou B, Luo BM, Feng X, Wen YL, Yang HY. Comparison of ultrasound elastography, mammography, and sonography in the diagnosis of solid breast lesions. J Ultrasound Med. 2007;26(6):807-15. [PubMed: 17526612].

26. Thomas A, Fischer T, Frey H, Ohlinger R, Grunwald S, Blohmer JU, et al. Real-time elastography-an advanced method of ultrasound: First results in 108 patients with breast lesions. Ultrasound Obstet Gynecol. 2006;28(3):335-40. doi:10.1002/uog.2823. [PubMed:16909438].

27. Tardivon A, El Khoury C, Thibault F, Wyler A, Barreau B, Neuenschwander S. [Elastography of the breast: a prospective study of 122 lesions]. J Radiol. 2007;88(5 Pt 1):657-62. [PubMed: 17541358].

28. Lee SH, Chang JM, Kim WH, Bae MS, Cho N, Yi A, et al. Differentiation of benign from malignant solid breast masses: comparison of twodimensional and three-dimensional shear-wave elastography. Eur Radiol. 2013;23(4):1015-26. doi: 10.1007/s00330-012-2686-9. [PubMed: 23085867].

29. Athanasiou A, Tardivon A, Tanter M, Sigal-Zafrani B, Bercoff J, Deffieux $\mathrm{T}$, et al. Breast lesions: quantitative elastography with supersonic shear imaging-preliminary results. Radiology. 2010;256(1):297-303. doi: 10.1148/radiol.10090385. [PubMed: 20505064]. 
30. Sadigh G, Carlos RC, Neal CH, Wojcinski S, Dwamena BA. Impact of breast mass size on accuracy of ultrasound elastography vs. conventional B-mode ultrasound: a meta-analysis of individual partici- pants. Eur Radiol. 2013;23(4):1006-14. doi: 10.1007/s00330-012-2682-0. [PubMed: 23085865]. 